\title{
Stanisław Grodziski
}

\section{Z dziejów spiskiego zastawu uwag kilka}

\section{Einige Bemerkungen zur Geschichte des Zips-Pfandes}

1. Ustanowienie zastawu miast spiskich. 2. Spisz niegrodowym starostwem pod zastawnym panowaniem władców Polski. 3. Likwidacja spiskiego zastawu.

Aneks.

1. Die Bestimmung des Pfandes der Zips-Städte. 2. Zips als nicht städtische Starostei, als Pfand unter der Regierung polnischer Herrscher. 3. Die Liquidation des Zips-Pfandes.

- Annex.

1. W czasach I Rzeczypospolitej szczególną rolę odegrał pewien zastaw - zatem instytucja z zakresu prawa rzeczowego, służąca do zabezpieczenia praw wierzyciela. Był to zastaw 13 miast, dwóch dominiów i kilkunastu wsi spiskich ${ }^{1}$. Dokonal tego zastawu cesarz Zygmunt Luksemburski, pożyczając od Wladysława Jagielly ogromną na owe czasy sumę 37 tysięcy kóp groszy praskich.

Do transakcji doszło przy okazji spotkania obu władców, jakie nastąpiło wczesną wiosną 1412 r., kiedy Jagiełło przebywał w Nowym Sączu. Zygmunt (który formalnie koronę cesarską przyjąl dopiero w 1433 r.), znajdujący się wówczas w nieodległym Kieżmarku, zaproponował spotkanie i odbycie rozmów. Doszlo do tego na pól drogi - w Lubowli nad Popradem, zatem po węgierskiej stronie; gospodarzem konferencji był więc Zygmunt. W wyniku tych rozmów obydwaj władcy 15 marca $1412 \mathrm{r}$. podpisali traktat o wzajemnej przyjaźni ${ }^{2}$. Stanowił on między innymi - co zyskało z czasem znaczenie dla omawiancgo tu problemu - że ewentualne spory graniczne $w$ tym rejonie poddawane będą sądowi polubownemu (iudicibus hinc inde ex utraque parte

\footnotetext{
1 Mape tego terytorium (niestety schematyczna i mało czytelną) podaje J. R adziszew ska, Studia z dziejów ustroju Spisza, Katowice 1969, s. 69.

${ }^{2}$ M. Dogiel, Codex diplomaticus Regni Poloniae et Magni Ducatus Litvaniae, L. I, Vilnae 1756, nr IX, s. $46-48$.
} 
deputatis) $)^{3}$. Następnie Zygmunt namówil Jagiełłę do wycieczki w głąb Węgier, a wiedząc, że Zakon Krzyżacki przekazał Polsce większą sumę pieniężną, skorzystał $\mathrm{z}$ okazji i wyprosil ową pożyczkę.

Dokument $\mathrm{w}$ sprawie zastawu miast spiskich wystawiony zostal przez Zygmunta $w$ Zagrzebiu 8 grudnia $1412 \mathrm{r}^{4}{ }^{4}$ Stanowił on, że wymienione w nim miasta pozostaną tak dlugo w posiadaniu Korony Polskiej, dopóki król węgierski, po dwumiesięcznym zawiadomieniu, nie wykupi ich za tęże sumę. Król polski zobowiązał się, że uszanuje miejscowe prawa i przywileje, a po odebraniu pożyczonej kwoty, terytoria te natychmiast zwróci Koronie węgierskiej.

Motywy, jakimi kierowali się obydwaj monarchowie, nie mają znaczenia dla omawianego tematu. Wystarczy więc tylko powiedzieć, że Władysław Jagiełlo pragnąl skłonić Zygmunta, by zaprzestał udzielać pomocy dyplomatycznej Zakonowi Krzyżackiemu, Zygmunt zaś, stale borykający się $\mathrm{z}$ kłopotami pieniężnymi, chciał zdobyć środki finansowe na wojnę $\mathrm{z}$ Wenecją o Dalmację. Być może zakładal, że sukces w tej wojnie pozwoli mu zwrócić pożyczkę i odebrać miasta spiskie; liczył też może na wzmocnienie swojego znaczenia w związku z przygotowywanym soborem w Konstancji. W walce z Wenecjanami nie odniósł jednak sukcesu, a sprawa Jana Husa na soborze osłabiła jego pozycję $i$ to nie tylko w Czechach. Do końca życia obu monarchów - Jagiełlo zmarł w 1434 r., a Zygmunt przeżył go tylko o 3 lata - nic się $w$ tej sprawie nie zmieniło.

2. Jak się kształtowała sprawa spiska w późniejszych czasach? Na Węgrzech o miastach spiskich nie zapomniano. Starał się je odzyskać król Maciej Korwin, ale na podstawie pokoju zawartego z Kazimierzem Jagiellończykiem w Spiskiej Starej Wsi w 1474 r., status quo został w pełni potwierdzony ${ }^{5}$. Nic też się nie zmienilo za panowania Władysława Jagiellończyka - króla Czech i Węgier. Jednakże sejmy węgierskie od drugiej połowy XVI w. po drugą połowę XVIII stulecia ponad dwudziestokrotnie domagały się od monarchii

\footnotetext{
${ }^{3}$ Ibidem, s. 48.

${ }^{4}$ Tekst podajemy w Aneksie; por. też: Codex diplomaticus Hungariae, t. X, vol. V, ed. G. Fejer, Buda 1842 , s. 297-301. Nietrafne jest natomiast to, co podaje A. D ive k y (Dzieje przylaczenia miast spiskich do Wegier $w$ roku 1770, Zamość 1921, s. 5), jakoby akt ten znajdował się też u Dogiela. Ani traktat lubowelski, ani towarzyszący mu akt umacniający przysięgą pokój między Polską a Węgrami, dokonany w Liblio, czyli Lubowli, o zastawie nie wspomina (por. M. Dogiel, Codex..., t. I, nr IX, s. 46-48, i nr X-XI, s. 49-50).

${ }^{5}$ Por. M. Dogiel, Codex..., t. I, nr XXVI, s. 69-71, oraz nr XXVIII, s. 73-75. W tym drugim akcie wspomniane są confines Regnum Hungariae [...] prope Antiquam Villam iuxta flumen Dywnawicz [czyżby Dunajec?] in comitatu Scepusiensi.
} 
wykupienia zastawu 6 . Było to już w czasach, kiedy korona węgierska znajdowała się w rękach Habsburgów, zatem decyzje o wykupie zapaść mogły jedynie we Wiedniu.

Granica polsko-węgierska, dodatkowo skomplikowana na Spiszu (zastawione Polsce miasta spiskie stanowiły porozrzucane enklawy na węgierskim terytorium), podlegała - co zrozumiałe $-\mathrm{z}$ obu stron rozmaitym naruszeniom. Zgodnie jednak z przyjętą w $1412 \mathrm{r}$. zasadą, spory rozstrzygane były przez komisje polubowne, których orzeczenia, nieraz niebanalne, cieszyły się szacunkiem ${ }^{7}$. Zdarzały się nawet wypadki niezależnego regulowania niemal równocześnie spraw na Spiszu przez władców Węgier i Polski, z wzajemnym naruszaniem kompetencji ${ }^{8}$. Istoty zastawu to jednak nie zmieniało.

Sytuacja prawna, jaka powstała w wyniku umowy z 1412 r., była jasna. Był to zastaw wyliczonych $w$ umowie nieruchomości. Zastawnik, czyli strona polska, obejmowal te nieruchomości w posiadanie i użytkowanie, $\mathrm{z}$ prawem pobierania pożytków płynących $\mathrm{z}$ tego użytkowania (a były to pożytki niemałe, gdyż Spisz był krainą dobrze zagospodarowaną). Ponieważ zastawca nie określil terminu wykupu, przyjąć należy, iż był to szeroko wówczas znany zastaw antychretyczny, w którym wykup był prawem, a nie obowiązkiem zastawcy. Zastaw taki porównywany mógł być też do umowy kupna-sprzedaży z prawem odkupu?.

Jasna była też sytuacja Spisza w świetle polityki Korony Polskiej. W tytulaturze monarchów polskich, od Władysława Jagielly do Stanisława Augusta Poniatowskiego, Spisz nie był wymieniany jako ziemia koronna. Nie jest to tylko argumentum ex silentio, gdyż zdarzały się także sformulowania świadczące

\footnotetext{
${ }^{6}$ A. Diveky, (Dzieje..., s. 6) wspomina, iż po sejmie 1717 r. dwór wiedeński podjął nawet akcje dyplomatyczną, zapewne celem wejścia w procedurę wykupu, choć - jak wolno przypuszczać - za zaniżoną sumę. Akcji tej Wiedeń skutecznie nie kontynuował. O Spiszu jednak we Wiedniu pamiętano, gdyż kanclerz Kaunitz polecił opracować w $1764 \mathrm{r}$. deductio iuris, tj. wywód praw korony węgierskiej do tego terytorium. Wymagane referaty, podkreślające jednak zastany charakter dzierżenia polskiego, zostały opracowane (ibidem, s. 7).

${ }^{7} \mathrm{Na}$ tej górze [Raczy w Żywieckim - S.G.] przedtem byly wielkie różnice $i$ zawady o granice wegierskie [...], aż tam commissja albo rada panów zjechala, gdzie za rozsqdkiem rajców do zgody przyslo: wina kielka beczek z Wegier przywiózszy, kazali na wierzchu góry samym jedne $i$ drugq beczke wina rozciqc; gdzie na obie strony wino rozlalo sie, $i$ co na wegierskq strone lalo sie, to odtqd granice wegierskie, a gdzie na polskq, to żywieckie uznali, i tak na wieczne czasy pokój przyrzekli (Chronografia albo Dziejopis żywiecki, wyd. St. Grodziski i I. Dwornicka, Żywiec 1987, s. 8).

${ }^{8}$ Np. w 1564 r. król Zygmunt August potwierdził miastu Sobocie przywileje, a w 1567 r. 10 samo uczynił cesarz Maksymilian II, por. J. R adziszewsk a, Studia..., s. 24.

${ }^{9}$ Por. J. Bardach, Historia państwa $i$ prawa Polski, t. 1, wyd. 2, Warszawa 1964, s. 503; St. P laza, Historia prawa w Polsce na tle porównawczym, cz. I: X-XVIII w., Kraków 1997, s. $287 \mathrm{i}$ n. Blizej problematyke zastawu w ówczesnej praktyce sądowej badał Z. R y ma s zewski, Zastaw osoby w malopolskich zapiskach sqdowych $X V$ wieku, Zesz. Nauk. Ut 1961, Ser. I, Prawo, nr 22); te nże, Zastaw w swietle praktyki sqdów malopolskich wXV wieku, ibidem, 1962, nr 26.
} 
jasno o tym, że Spisza nie zaliczano do Korony ${ }^{10}$. Zgodnie ze zobowiązaniem podjętym w 1412 r., XIII civitates scepusienses oppignoratae otrzymały od Władysława Jagiełły potwierdzenie swoich - od węgierskich wladców nadawanych - praw i przywilejów. Miasta spiskie zachowały własne prawodawstwo i sądownictwo, a ludność szlacheckiego pochodzenia nie brała żadnego udziału w sejmikach i sejmie Rzeczypospolitej. Nie obowiązywalo także na Spiszu polskie ustawodawstwo - konstytucje sejmowe od $1493 \mathrm{r}$. aż po rok 1769. Nie są też znane protesty, gdy władcy węgierscy podkreślali formalną przynależność Spisza do Węgier ${ }^{11}$. Mimo to zastaw spiski odgrywal niebłahą rolę w politycznych i kulturalnych dziejach Rzeczypospolitej ${ }^{12}$.

Terytorium to traktowane było na prawach królewszczyzny i tworzyło w obrębie Korony starostwo niegrodowe. Że zaś było ono bogate, przeto przydzielano je w dożywocie znacznym i wpływowym dostojnikom ${ }^{13}$. Wszelkie prośby i skargi ludność miejscowa zanosiła - bezpośrednio lub za pośrednictwem starosty - do samego monarchy, który występował wobec niej także jako pan feudalny ${ }^{14}$. Spraw takich, zresztą pozytywnie dla Spisza załatwianych, Metryka Koronna zanotowała wiele ${ }^{15}$. Niekiedy sprawy te,

${ }^{10}$ Konstytucja sejmu warszawskiego z 1609 r. Opatrzenie zamku Lubowle, VL, t. II, s. 1676-1677, mówi, iż Nam wiele zależy na zamku Lubowli $i$ miasteczkach spiskich, które: leżq extra Regnum. [podkr. moje - S. G.].

11 J. R adziszewsk a, Studia..., s. 124.

${ }^{12}$ Poprzez Lubowlę, korzystając $z$ jej silnego zamku, wracał do kraju Jan Kazimierz podczas „potopu" szwedzkiego. Zatrzymał się w niej też, wracający z wyprawy wiedeńskiej, Jan III Sobieski. W Podolińcu Stanisław Lubomirski założył w 1642 r. kolegium pijarskie, w którym był nauczycielem, i $z$ którego wyszedł Stanisław Konarski.

${ }^{13}$ Wśród ważniejszych starostów spiskich z XV w. wymienić należy Jana Gładysza (któremu Jagiełło powierzył tę funkcję z powodu doskonałej znajomości języka węgierskiego), Zawiszę Czarnego, Piotra Szafrańca z Pieskowej Skały i Mikołaja Komorowskiego. W XVI w. zarządzali Spiszem: Stanisław Kmita, Andrzej Kościelecki, Piotr Kmita, Jan Boner, Sebastian Lubomirski. Odtąd przez XVII i połowę XVIII w. pozostawał Spisz w rękach starostów $z$ rodu Lubomirskich. W 1746 r. August III nadał starostwo spiskie swej własnej żonie - Marii Józefie Habsburg, córce cesarza Józefa I; w jej imieniu zarządzał tym terytorium minister Henryk Brühl. Ostatnim starostą spiskim pod rządami polskimi był Kazimierz Poniatowski - starszy brat króla.

I4 J. Radziszewska, (Studia..., s. 169-175) zamieścita w aneksach in extenso ważne akty prawne, skopiowane $z$ rękopisów archiwum Lewoczy: mandat króla Kazimierza Jagiellończyka: z 1459 r. do starosty Przecława w sprawie obciążeń ludności; Zygmunta I zwolnienie Spiszan od powinności na skutek klęski elementarnej, z 1542 r.; Zygmunta Augusta zakaz pobierania cel, z 1551 r.; tegoż monarchy decyzja w sprawie obciążeń ludności, z 1555 r.; rozporządzenie w sprawie czynszów z $1572 \mathrm{r}$.

is Matricularum Regni Poloniae Summaria, Varsaviae 1910 i n., pars IV, vol. 1-3, wspominaja dokumenty spiskie pod numerami: 1316, 1601, 1905 (powinności poddańcze); 2481 (komisja polsko-węgierska); 2484 i 2485 (zbiegostwo chłopów); 2487 (przywilej górniczy); 2686 (potwierdzenie praw spiskich z 1539 r.); 6292 (potwierdzenie przywilejów cechowych); 7435, 8171 (potwierdzenia przywilejów kościoła z 1548 r.); 8172 (potwierdzenie przywilejów cechowych z 1548 r.); 8365, 8735 (przywileje górnicze); 8746, 8778, 8893 (sprawa ciężarów 
zwłaszcza jeśli szło o bezpieczeństwo całego Spisza i południowej granicy Rzeczypospolitej, trafiały do sejmu. Sejm więc podczas konfederacji warszawskiej $1587 \mathrm{r}$. postanowił, iż na zamku spiskim w Lubowli stacjonować będzie stały garnizon ${ }^{16}$. Konstytucja ta była konsekwencja zdarzenia, jakie miało miejsce w tym roku, gdy wojska Maksymiliana Habsburga, wkraczające do Rzeczypospolitej w związku $\mathrm{z}$ próbą objęcia przezeń tronu polskiego, z marszu zdobyły Lubowlę i obsadziły ją załogą.

Konstytucja sejmu warszawskiego 1658 r. pt. Fortece Rzeczypospolitej stanowiła: Jako sila na tym należy, aby fortece Rzeczypospolitej, tak miasta stoleczne jako też i pograniczne, osobliwie Kraków, Warszawa, Poznań, Lwów Kamieniec, Lubowla swoje od roku do roku zawsze praesidia mialy [...] warujemy $i$ mieć chcemy, aby te miasta calej Rzeczypospolitej kosztem praesidia mialy [...] A że dla szczuplości ordynaryjnego żoldu praesidium Lubowle in eo numero na sto ludzi trzymane być nie może, tedy żold ich $i$ placq cum praesidio Kamieńca porównywamy i placq onym z kwarty na sto $i$ dwadzieścia ludzi naznaczamy ${ }^{17}$.

Owa ochrona odgrywała istotne znaczenie dla calego Spisza nie wobec zagrożeń militarnych, te bowiem w następnym pólwieczu trafiały się rzadko i nie dotyczyły bezpośrednio okolic Lubowli. Na pewno podtrzymywała powage Rzeczypospolitej i zapobiegała jakimś prywatnym działaniom niesfornych węgierskich magnatów. Na codzień miała istotne znaczenie dla bezpieczeństwa życia i mienia mieszkańców wobec zbójnictwa tatrzańskiego; w stosunku do tych zagrożeń załoga Lubowli była siłą wystarczającą.

poddańczych); 10687, 11378 (powinności poddanych); 12561, 13871 i 13876 (przywileje górnicze); 13924, 14283, 14294, 14315, 15146, 15360, 15537, 15741, 16460, 16935, 20276, 20853, 21327, 21957, 22897, 23416, S 1214.

${ }_{16}$ VL, t. II, s. 1066. Zamek spiski miało obsadzić 50 jezdnych i 100 pieszych, a oprócz nich stacjonowało też w nim 150 jezdnych wojewody krakowskiego. Konstytucja sejmu warszawskiego z 1609 r. (por. wyżej przyp. 10) zmniejszyła tę załoge, mimo iż sytuacja polityczna bynajmniej nie polepszyła się: Iż Nam wiele zależy na zamku Lubowli i miasteczkach spiskich, które [...] wielkq sq tej Rzeczypospolitej od każdego nieprzyjaciela zaslonq, a teraz pod tymi mieszaninami częstokroć wojska tamtędy cudzoziemskie przechodzq, zaczym zawsze niebezpieczérstwa [...] obawiać sie potrzeba, przeto $w$ czas to opatrujac, staroście naszemu lubowelskiemu za pozwoleniem wszech stanów obojga narodu pozwalamy z kwarty (tak jako i na Kamieńcu) placq ustawicznq na sto piechoty dla obrony zamku tamtego i przechodów ludzi cudzoziemskich do państw naszych, póki Rzeczpospolita tamtemu miejscu inszego opatrzenia nie obmyśli. A ta piechota, aby in pleno numero ustawicznie na zamku byla.

$17 \mathrm{VL}, \mathrm{t}$. IV, s. 551. Konstytucja sejmu warszawskiego z 1670 r. Preasidium Lubowle uzasadniając, iż Lubowla, kiedy pokoju od pogan dotqd nie jesteśmy pewni, osobliwego opatrzenia potrzebuje (może wobec możliwości ataku tureckiego z Niziny Węgierskiej, poprzez Słowację, na Polskę), utrzymała załogę złożoną ze 120 żołnierzy (VL, t. V, s. 67). 
3. Niestety, sytuacja ta uległa zmianie na niekorzyść od początku XVIII w. Przypomnieć trzeba, iż stanowił Spisz terytorium szczególne: od Rzeczypospolitej oddzielone były owe 13 miast posiadłościami węgierskimi. Aby dostać się do Podolińca czy Lubowli, tworzących jakby wyspy polskie wewnątrz państwa węgierskiego, trzeba było przekroczyć granicę węgierską pod Muszyną lub Piwniczną i posuwać się na południe, wzdłuż Popradu. Prosty podróżnik granicę tę przekraczał bez żadnych przeszkód, ale siły zbrojne budziły natychmiast czujność węgierską. Kiedy Szwedzi zajmowali w 1655 r. Polskę, zdobyli Kraków i doszli pod Piwniczną, Spisza nie tknęli, nie chcąc naruszać granicy węgierskiej. Przewidywał to marszałek wielki koronny Jerzy Lubomirski i dlatego uwiózł z Krakowa i schronił w Lubowli polskie insygnia koronacyjne. Jego wnuk - Teodor Lubomirski - walcząc po stronie Stanisława Leszczyńskiego przeciw Augustowi II, parokrotnie chronił się na Spiszu przed wojskami saskimi czy rosyjskimi, dając się zresztą tak we znaki ludności miejscowej, że go nazywano „księciem piekielnym". O jego kampaniach ludność ta mawiała, że $w$ ten czas wychodzil $w$ pole, kiedy się nie bylo z kim bić, a kiedy wojsko jakie nastapilo, to (cofal sie) na Lubowniq jako smok do jamy ${ }^{18}$.

Tę samą taktykę przyjęli później konfederaci barscy, nieraz wprost chroniąc się pod habsburską opiekę w przekonaniu, że będzie ona bezinteresowna. „Generalność”, czyli centralna władza konfederacka, rezydowała bądź w Białej, czyli na samej granicy Śląska Cieszyńskiego, bądź w Preszowie - zatem już po węgierskiej stronie. Za przykładem dowództwa postępowali i konfederaccy żołnierze; niejeden $z$ oddziałów obierał sobie bazę operacyjną na samej granicy. W takiej sytuacji dochodziło nieraz do naruszeń granicy przez wojska konfederackie czy rosyjskie ${ }^{19}$. Sytuacja ta przyciągała coraz większą uwagę Wiednia.

Jedno $\mathrm{z}$ takich wydarzeń na terenie Spisza okazało się brzemienne w smutne skutki. Dowódca konfederacki Józef Bierzyński postanowił zaatakować na Spiszu królewskiego brata - Kazimierza Poniatowskiego, ówczesnego starostę. Przekroczyl więc granicę i uderzył na Lubowlę, ale został odparty przez załoge zamkową. Jedynym skutkiem tej eskapady było to, iż Poniatowski, który utrzymywal stałe kontakty z Wiedniem, poprosil o obsadzenie starostwa spiskiego wojskiem austriackim ${ }^{20}$. Prośba jego została natychmiast spelniona. Nie w taki jednak sposób, jak to sobie wyobrażał książę Poniatowski, ani bynajmniej nie po myśli doradców konfederackich. Kiedy na domiar zlego pod miejscowością Granaszto na Spiszu doszło do krwawej potyczki między konfederatami a przybyłymi ich

\footnotetext{
${ }^{18}$ Por. St. Grodziski, Kronika jazowska. Zapiski do dziejów Sądeczyzny z lat 1662-1829, Teki Archiwalne 1971, t. XIII, s. 208-211.

19 W. Konopczyński, Kazimierz Pulaski. Zyciorys, Kraków 1931, s. 148-151.

${ }^{20}$ W. Konopczyński, Bierzyński Józef, [w:] Polski slownik biograficzny, t. II, s. 86.
} 
śladem Rosjanami, w której konfederaci ponieśli klęskę, a ludność miejscowa straty, cesarzowa Maria Teresa wydała polecenie, aby zaciągnąć wzdłuż granicy polskiej kordon wojskowy. Uzasadniano to koniecznością zapewnienia bezpieczeństwa własnym poddanym, i to było prawdą; mówiono też o niebezpieczeństwie zarazy morowego powietrza, idącej od Polski, i to już prawdą nie było. W ciągu kwietnia i maja 1769 r. miasta spiskie, odcięte kordonem od Rzeczypospolitej i obsadzone przez wojska austriackie, zmieniły przynależność państwową. Symbolicznym tego wyrazem było wywieszenie w nich herbów $\mathrm{z}$ wizerunkiem orła cesarskiego ${ }^{21}$.

Bezsensowne, prowokujące wręcz potężnego sąsiada działania konfederatów i ich politycznych przeciwników nie zmieniają jednak faktu, że zagarnięcie Spisza jako zastawu, bez zwrotu pożyczonej ongiś ogromnej kwoty, pozostawało bezprawiem.

Podsumowując ten zarys wydarzeń, stwierdzić należy, iż władze austriackie miały pelną świadomość tego, iż dokonaly agresji. Nie tylko dlatego, iż we Wiedniu znano polskie prawa do Spisza. General Andrzej Mokronowski, upoważniony przez króla Stanisława Augusta w 1769 r., dał do zrozumienia dworowi wiedeńskiemu, że Warszawa przyjmie jakąś mniej lub bardziej symboliczną sumę wykupu. Propozycja Mokronowskiego spotkała się z milczeniem; po cóż było wykupywać teren, który się już posiadało za darmo? Zresztą, jak wiadomo, w następnym roku (1770) wojska austriackie posunęły się w głąb Rzeczypospolitej, zajmując starostwa nowotarskie, czorsztyńskie i sądeckie. Były to kroki prowokujące dalszą grabież ziem Rzeczypospolitej.

W traktacie, zawartym między Rzeczpospolitą a Cesarstwem Habsburskim i „potwierdzonym" 18 września 1773 r. na sejmie, opisującym teren zaboru austriackiego, dokonanego w $1770 \mathrm{r}$., o Spiszu nie wspomniano ani słowem ${ }^{22}$. Nie poruszono też tego problemu w oficjalnym ,wywodzie praw" monarchii habsburskiej do ziem Rzeczypospolitej ${ }^{23}$. Zapewne dlatego, że wtedy wygodniej było uznać Spisz za teren zastawu, odebrany osobno.

Niestety, zastaw służący do zabezpieczenia praw wierzyciela, w tym wypadku praw tych nie zabezpieczyl.

21 A. Diveky, Dzieje..., s. 18-19.

22 VL, t. VIII, s. 20-21.

${ }^{23}$ Wywód ten, choć tak niewiele lat temu kanclerz $\mathrm{K}$ a unitz nakazał sporządzic deductio iuris (por. wyż. przyp. 6) zastaw Spisza wyrażnie chciał pominąć i nie wspomnial o nim podczas obszernego opisu wydarzeń 1412 roku (Wywód poprzedzający praw Korony Wegierskiej do Rusi Czerwonej $i$ do Podola, tak jako Korony Czeskiej do Ksiẹstw Oświecimskiego i Zatorskiego, druk. Trattnera, Wiedeń 1772, s. 75 i n.). Dopiero przy okazji opisu panowania Macieja Korwina mimochodem wspomniał o 13 miastach spiskich, zastawionych Polsce przez Zygmunta Luksemburskiego (s. 95-96). Sposób, w jaki Spisz przeszedł w ręce austriackie, wywód ten pominąi milczeniem. 


\section{ANEKS $^{24}$}

Nos Sigismundus Dei gracia Romanorum rex semper augustus et Hungarie rex etc. recognoscimus tenore presencium, quibus expedit universis, racione veri mutui nos a serenissimo principe domino Wladislao rege Polonie eiusque prelatis et baronibus triginta septem milia sexagenarum latorum grossorum monete et numeri Bohemicalium boni et iusti ponderis habuisse et cum effectu recepisse. Quemquidem dominum Wladislaum regem Polonie, successores, prelatos et barones ipsius in restitutione earundem pecuniarum assecurare cupientes et prout iustum est in solucione ipsum reddere cerciorem, sibi et eius successoribus, prelatis et baronibus terras, castrum nostrum Liblio alias Libowla cum opido et opidum Podolinecz cum fortalicio ac villis ad eas spectantibus, nec non civitatibus et opidis infrascriptis in terra nostra Supusiensi (sic) diocesis Strigoniensis situatis, videlicet Gnezna, Bela, Lewbecz, Meynharczdorff, Durolsdorff, Dewtschendorff, Michelsdorff, Filke, Walendorff, Kyrchendorff, Newdorff, Rewsdorff, Mathesdorff et Jurgenberg nuncupatas, cum earum omnibus pertinenciis, censibus, fructibus, redditibus, proventibus, iurisdicionibus temporalibus, possessionibus, agris, pratis, campis, lignis, silvis nemoribus, mellificiis, piscaturis, piscinis, lacubus, paludibus, aquis et aquarum decursibus, molendinis, emolimentis, quercetis, pinetis, virgultis, gays, mericis, aucupacionibus, venacionibus, exaccionibus ordinariis, obvencionibus, attinenciis et appendiis universis, quibuscumque nominibus vocitentur, nichil possessionis aut utilitatis pro nobis et successoribus nostris in eisdem reservantes, obligavimus et in vadium posuimus ac obligamus tenore presencium, voluntate prelatorum et baronum nostrorum ad hoc specialiter accedente; ita quod omnibus utilitatibus ac proventibus hic descriptis sine alicuius usure scrupulo idem dominus Wladislaus rex Polonie suique successores uti frui valeant et gaudere. Cui eciam omnes cives et incole terre, civitatum et villarum predictarum, tamquam nobis obedire et de singulis censibus, proventibus et obvencionibus interim, donec ab ipso vel eorum aliquo redimemus terras, castra et opida, civitates et villas easdem, respondere tenebuntur. Quasquidem terras, castra, civitates et villas predictus dominus Wladislaus rex Polonie, successores, prelati et

${ }^{24}$ Do tekstu S. Grodziskiego redakcja załącza zeskanowany z wydawn. Wł. Semkowicza (Wierchy 1930, R. 8, s. 152-155) akt zastawu 16 miast spiskich z 8 listopada 1412 r. 
barones ipsius tenebunt, possidebunt et habebunt tamdiu, quousque sibi aut eius successoribus, prelatis et baronibus per nos aut successores nostros predicta trigintaseptem milia sexagenarum latorum grossorum monete Bohemicalium boni et iusti ponderis, aut valorem earundem in auro vel argento, fuerint efficaciter persoluta. Promittimus insuper bona fide in verbo nostro regio easdem terras, castra, civitates et villas ab omnibus iniuriis, impugnacionibus quorumcumque intraneorum ac si ea per nos possideremus, quamdiu idem dominus Wladislaus rex Polonie, successores ipsius ipsas tenuerint, defendere et tueri; eo eciam non obmisso, quod si aliquis de regno nostro Hungarie easdem terras et castra, civitates, opida et villas sub eodem domino Wladislao rege Polonie, successoribus, prelatis et baronibus ipsius receperit aut acquisiverit ipsas sine dolo et fraude reaquirere et ipsis eas restituere tenebimur et debemus; in casu autem, quo ipsas reaquirere non possemus, extunc sibi, successoribus, prelatis et baronibus ipsius predicta trigintaseptem milia sexagenarum reddere et solvere promittimus bona fide, vel alia bona consimilia et eiusdem valoris sibi et ipsius successoribus in eisdem obligare. Si autem hec facere non curaverimus aut neglexerimus, extunc ad omnia dampna, que ex non complecione promissorum nostrorum in presenti littera expressorum predictus dominus Wladislaus, successores, prelati, barones et Regnum ipsius perceperint, nos unacum omnibus prelatis et baronibus nostris resercienda, refundenda et solvenda submittimus, pro quibus Regni nostri homines cuiuscumque condicionis, dignitatis et preeminencie et bona ipsorum arrestare, captivare, terras nostras invadere, spoliare libere idem dominus rex Wladislaus, successores, prelati et barones ac Regnum ipsius possint et valeant absque omni resistencia et contradiccione nostra et nostrorum tamdiu, quousque sibi, suis successoribus, prelatis et baronibus et Regno per nos, nostros successores, prelatos et barones de omnibus premissis fuerit integre satisfactum. Dum autem predictas terras, castra et civitates, opida et villas ab eodem domino Wladislao rege Polonie, successoribus, prelatis et baronibus suis redimere et liberare voluerimus, extunc litteram nostram sub sigillo maiestatis nostre pendenti ad eundem dominum Wladislaum rcgem vel eius successores, prelatos et barones Regni eius scriptam debemus per notabiles duos proconsules, unum videlicet de Lewche et alium de Cassovia, ad capitaneum ipsius in Liblio dirigere et eam sibi facere presentari ac significando intimare in eadem, quod ipsas terras, castra, civitates, opida et villas infra duos 
menses continuos volumus ab eodem domino Wladislao rege vel eius successoribus, prelatis et baronibus liberare. Si autem nos decedere contigerit, extunc duo prelati et totidem barones maiores regni nostri Hungarie sub sigillis eorum pendentibus in hoc casu idem facere debebunt et tunc a die insinuacionis et assignacionis litterarum huiusmodi predicta trigintaseptem milia sexagenarum in grossis boni et iusti ponderis vel auro puro aut argento infra eosdem duos menses ad castrum Dunawecz duci debent et ibidem per homines predicti domini Wladislai regis Polonie, successorum, prelatorum et baronum eius, quos ad hoc duxerit deputandos, numerari et numerata sub salvo, securo et sufficienti conductu nostro successorum, prelatorum et baronum nostrorum in castrum Czornsteyn deportari et adduci. Interim autem in castro Dunawecz predicto quatuor pociores Poloni de terra Cracoviensi et Sandomiriensi vel altera earum, quos rex Hungarie vel barones ipsius regni Hungarie tunc nominaverint et elegerint, videlicet die intimacionis pro solvendis pecuniis et redempcione pignorum predictorum faciende, ita tamen, quod eligantur presentes aut in regno Polonie ubicumque existentes, non impediti tali infirmitate et impotencia, quod venire non possent, quo impedimento extante alii loco impeditorum transmittantur et per ipsum dominum Wladislaum regem Polonie, successores, prelatos et barones predictos in obstagium in eodem castro Dunawecz reponantur, nec abinde recedere valeant, donec castrum predictum Liblio ac alie civitates et opida predicta nobis aut successoribus nostris sive prelatis et baronibus integre fuerint restituta, nulla eciam excepcione, excusacione contradiccione vel occasione, obsistente. Harum, quibus nostrum et prelatorum ac baronum nostrorum sigilla sunt appensa testimonio litterarum. Et nos Johannes archiepiscopus Strigoniensis, Johannes episcopus Jauriensis et Nicolaus de Gara regni Hungarie palatinus, comes Symon de Rozgon iudex curie regie, Johannes de Pelsewcz magister tavarnicorum regalium, Ladislaus de Wylak banus Machouiensis, Johannes banus de Maroth, Petrus de Peryn comes Wyvariensis, Emericus de Peryn secretarius cancellarius regie maiestatis, De[...]va $\left(^{*}\right)$ de Syrke magister tavarnicorum reginalium, Johannes de Rozgon thesaurarius regie maiestatis, Matheus de Paloch comes Borsodiensis, Ladislaus de Pelsewcz filius condam Emerici wayuode, Johannes de Homonna, Benodictus Sudar de Makowicze, prelati et barones regni

* Wyraz w tekście uszkodzony. 
Hungarie promittimus bona fide pro nobis. et nostris successoribus predicta omnia per dominum nostrum regem de voluntate et beneplacito nostris facta, disposita et promissa inviolabiliter observare. In quorum fidem et testimonium unacum sigillo dicti domini nostri regis sigilla nostra presentibus sunt appensa. Datum Zagrabie, octavo die festi Omnium Sanctorum anno Domini millesimo quadringentesimo duodecimo, regnorum autem nostrorum anno Hungarie etc. vigesimo sexto, Romanorum vero tercio. 